\title{
Does Urban Design Influence Physical Activity in the Reduction of Obesity? A Review of Evidence
}

\author{
Alpana Sivam ${ }^{*}, 1$, Sadasivam Karuppannan ${ }^{1}$, Mohammad Javad Koohsari ${ }^{2}$ and Akash Sivam ${ }^{3}$ \\ ${ }^{I}$ Barbara Hardy Institute, School of Natural and Built Environments, University of South Australia, Australia \\ ${ }^{2}$ Melbourne School of Design, University of Melbourne, Australia \\ ${ }^{3}$ School of Medicine, University of Adelaide, Australia
}

\begin{abstract}
Obesity has risen progressively over the past three decades, and is a major health problem around the world. Biological, psychological, behavioural, and social factors are unable to fully explain or limit the obesity outbreak. Therefore, questions arise about whether a well-designed built environment (BE) can enhance desire and opportunity for physical activities including incidental exercise and recreation in the local community.

Many studies in public health have confirmed that physical activity (PA) can help prevent obesity and PA has become a public health priority in modern societies. With individual policies often failing to encourage PA, there has been much focus upon various ecological models that emphasise importance of the BE in promoting PA. Structure and quality of the $\mathrm{BE}$ can influence the need, the desire or the opportunity for people to walk, cycle and undertake PA as part of daily routine, incidental exercise for recreation. Thus, the question arises whether urban design being a multidimensional design tool could help improve the BE of neighbourhoods and encourage PA.

This paper aims to review evidence related to the influence of conceptual urban design qualities in the improvement of PA and to summarise guidelines to promote PA through these qualities. The method adopted to address this aim involves a content analysis of available academic literature, with focus on the public health, planning, transport and urban design fields. The findings demonstrate that in spite of some contradictory evidence, many studies have confirmed that good urban design qualities can play a partial role in encouraging PA.
\end{abstract}

Keywords: Perceptual urban design qualities, obesity, public health, built environment, physical activity.

\section{INTRODUCTION}

Obesity affects all age and socio-economic groups. It has been observed worldwide, that more people suffer conditions related to being overweight and obese rather than from malnutrition and being underweight [1]. Furthermore, being overweight or obese is responsible for $5 \%$ of global mortality [2]. Obesity also accounts for 2 to $6 \%$ of total health care costs in several developed countries [3]. It is also recognised as major threat to public health [4] and is a real concern for both governments and communities. For example, in $2007-2008,37 \%$ of adults in Australia over age 18 were overweight, and a further $25 \%$ were obese [5]. A higher percentage of men suffered from being obese or overweight than women ( $68 \%$ of men compared to $55 \%$ of women) [5].

Being obese results from a range of complex reasons, including, but not limited to, genetics, diet, physical inactivity, socio-economic conditions, economic growth, modernisation, urbanisation and the globalisation of the food market [3]. While genetics may contribute to the risk of being either overweight or obese, the fundamental cause is an imbalance between the levels of energy consumption

*Address correspondence to this author at the School of Natural and Built Environments, University of South Australia, Australia; Tel: +6188302 1850; Fax: +61 88302 2252;

E-mails: Alpana.Sivam@unisa.edu.au, alpanasivam@yahoo.com verses the level of energy expended by an individual [6] Somehow, biological, psychological, behavioural, and social factors are unable to reduce the percentage of obese and overweight people in the society [7]. These findings have led to a new research paradigm to help understand the relationship between the built environment $(\mathrm{BE})$ and the obesity trend.

It is argued that the design of the BE plays a critical role in the increase or decrease of physical activity (PA), which has a direct impact on decreasing the level of obesity within a community [8-10]. The BE encompasses a broad range of physical and social elements that comprise the structure of a community and may have influence upon the overall levels of overweight and obese individuals. During the last decade, there has been a marked increase of literature examining the relationships between the BE and PA, especially in the realm of public health [4, 7, 11-15]. Lopez and Hynes [15] argue that urban design elements, such as density, poor street connectivity and the lack of sidewalks are associated with decreased PA and lead to an increase in weight.

In another study, Lopez [16] demonstrated that urban sprawl was associated with an increased risk of being overweight or being obese. However Kelly-Schwartz et al., [17] claim, "measures of sprawl have no significant relationship to (the) frequency of walking, body mass index, or diagnosis of various chronic diseases. However, among those with chronic conditions, including hypertension, 
diabetes and lung disease, those who live in the areas with more highly connected street network have higher rated health."

Saelens et al., [18] argue that people living in traditional neighbourhoods, with a gridiron layout pattern, high densities, mixed land use and short block lengths generally travel walking and/or cycling than people living in sprawl type of BE. 'Commercial land use and access to shops and walking destinations have been proposed as components of a neighbourhood's "walkability" shaping PA choices and obesity risk' [19].

Some studies argue that the unavailability of recreational facilities for formal PA is associated with obesity or being overweight $[20,21]$. Fear of crime and violence also restrict residents walking $[19,22]$. These studies show how PA is very important for healthy living including reducing obesity as well as how the BE plays a pivotal role in encouraging PA at both neighbourhood and city scales.

The BE includes various elements of urban design which can help creating a healthy neighbourhood. The form of the BE can encourage or discourage PA [7, 23]. For example, neighbourhoods with good legibility, permeability, recreational and community facilities, mixed land use and which are safe can encourage PA, whereas as areas with few recreational facilities that are not safe can hinder PA $[7,18]$.

Land use pattern, transport system, safety and site design are several elements of the BE that relate to PA [13]. There is growing consensus among researchers and policymakers that the social and physical environment plays an important role in promoting PA [7]. A number of studies have found direct or indirect links between the $\mathrm{BE}$ and obesity. For example, elements of design such as street connectivity, presence of pavements, shops within walking distance, parks and playgrounds in accessible locations and aesthetically pleasing neighbourhoods can encourage overall PA [18, 24, 25].

This study aims to examine the relationship between "perceptual urban design qualities" and PA through review of current literature using content analysis. This study is limited to identification of urban design principles and explore how these urban design principles may improve the $\mathrm{BE}$ to encourage $\mathrm{PA}$, as well as help reduce the risk of obesity.

\section{CONCEPTUAL FRAMEWORK AND METHOD}

The conceptual approach of this study was the social ecological approach. This multidisciplinary approach incorporates various issues such as the social and physical environment and policy implications [26]. This approach enabled the authors to examine the interrelationships between physical environment and PA. The conceptual model of the study draw on the social ecological approach, as well as the model developed by Ewing et al., [27] that seeks to improve walkability through urban design qualities.

Urban design literature identifies numerous perceptual urban design principles of the BE which might influence PA such as walking, cycling and exercising. The perceptual urban design principles used to create successful places [28$31]$ include development intensity, land use mix, fine grain economy, adaptability, permeability, streets, contact, visibility and horizontal grain, public realm, movement, green space and water space, landmarks, legibility, comfort, diversity, richness, continuity, contrast, intelligibility, interest, intimacy, openness, rhythm, texture, and human scale.

From this list, five urban design principles were selected: permeability; vitality and diversity; legibility; richness and open space; to explore the relationship between design principles and PA. The definitions of these principles were based on the urban design literature. Fig. (1) presents this process.

The research methodology is divided into two distinct sections. The first section explores the means to encourage PA through better perceptual urban design qualities. It identifies and defines the aforementioned urban design principles as well as the relationship between behaviour relating to PA and these principles. This is mainly based on findings from literature and research conducted in health and urban design disciplines. The second section presents the findings of the study. The last section summarise guidelines to encourage PA through these qualities.

\section{PROMOTING PA THROUGH BE-TTER PERCEP- TUAL URBAN DESIGN PRINCIPLES}

The definition of urban design adapted in this research is as following:

"Urban design is multifaceted discipline dealing with a range of social, economic, transport, infrastructure and cultural aspects that have an ongoing impact on the functioning and form of the urban environment" [32].

The urban design approach provides an overall framework to guide policy development and government initiatives in planning, provision of infrastructure and private development, as well as helping to create liveable neighbourhoods. This approach also address long term planning strategies including land use structure, vision and character of the place, improvement of legibility and permeability of a place and encourage community participation in regards to physical and social activities. Urban design is concerned with both the structure and the function of cities.

Several urban design principles help improve the BE and encourage residential ties, social inclusion and PA. Thus, urban design is noted as:

"the art of making places for people. It includes the way places work and matters such as community safety, as well as how they look. It concerns the connections between people and places, movement and urban form, nature and the built fabric, and the processes for ensuring successful villages, towns and cities" [33].

A responsive urban environment, however, is not merely the physical enhancement. It is well recognised that the essential element of place-making involves activity, image, and form. Therefore, these three elements are considered as the main urban design principles. Each element can be further expanded into sub-design principles. Selections of these examples are shown in Fig. (2). 

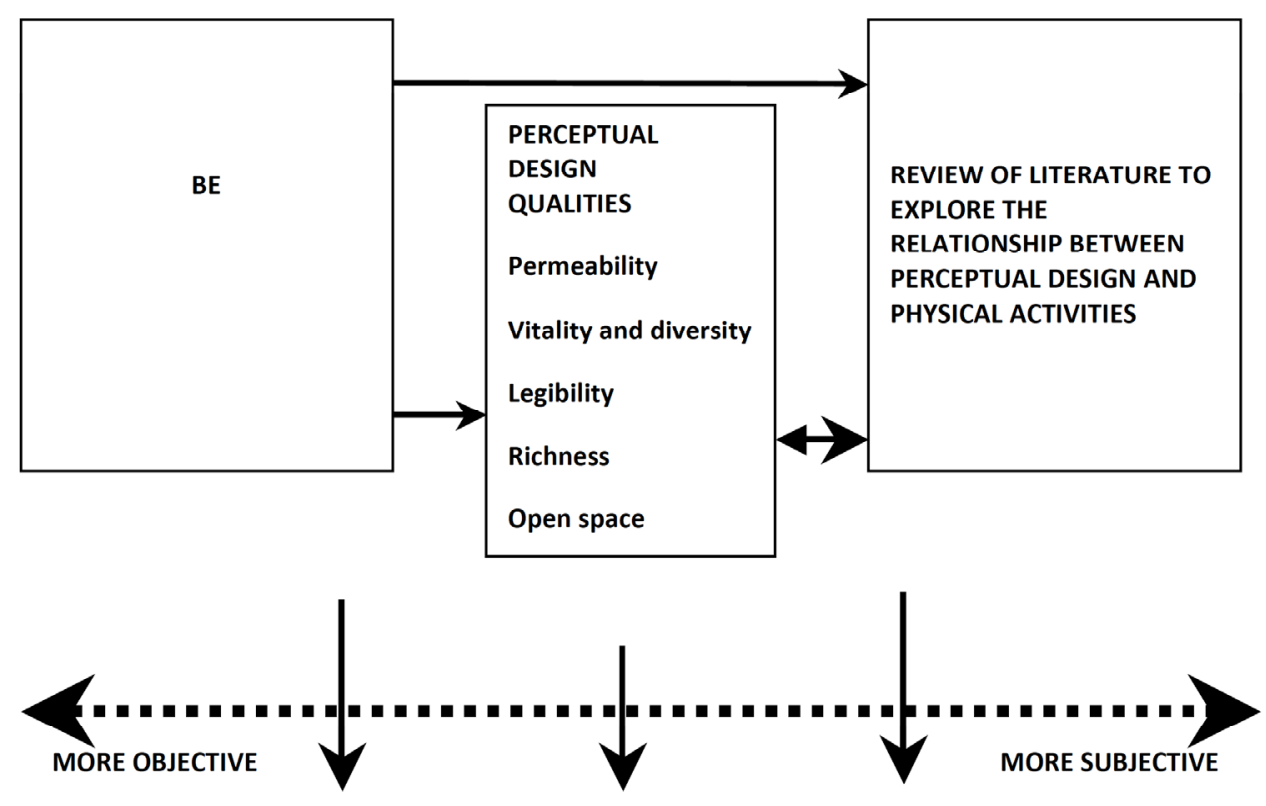

PA BEHAVIOUR

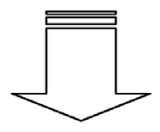

\section{RELATIONSHIP BETWEEN PA AND URBAN DESIGN PRINCIPLES}

Fig. (1). Conceptual framework. Source: Adapted from [27].

The extensive literature review provided an array of specific urban design principles relating to PA and the BE. These principles were then prioritised, narrowed down to five most common of urban design principles applicable for investigation. The perceptual urban design principles is explained in the following section.

\section{PERCEPTUAL URBAN DESIGN PRINCIPLES}

The role of identified urban design principles in promoting PA is explained as below.

\section{Permeability}

Permeability promotes connection within and between spaces as well as linking surroundings with more than one route of access [31]. In order to direct people to various spaces, alternative routes need to be visual, if, for example, they are not familiar to a place [30]. This will ultimately encourage the use of wide range of places and spaces.

Both physical and visual permeability is important as to create a high quality BE, and is achievable through legible layout pattern. Street layouts are important, with streets and paths well connected to multiple destinations, in order to encourage walking and cycling. Greater the amount of streets, alleys and corners, more permeability an area has and it makes its users feel more safe. Montgomery does provide guidelines on permeability issues and states that a city block should not exceed $90 \times 90$ metres. In addition, rather than buildings being placed centrally in this area with setbacks from the street and with surrounding open space, buildings should be built up to the street with public open space located to the centre of the block [29].

A walkable neighbourhood needs to be permeable to provide 'easy access to local destinations and public transportation services' [34]. A development with many culde-sacs also can make it almost impossible for pedestrians to travel through the development. However, developments with lots of streets and smaller blocks not only allow for higher level of physical permeability, but also increase visual permeability through 'improving people's awareness of the [travel route] choices available' [30]. Cul-de-sac developments, however, generally make walking trips to local services and public transport longer.

The length of a block also plays an important role in creating visual connection with the community, as well as increasing social capital. It is likely that the segregation of pedestrian and vehicular traffic reduces permeability [30]. Therefore, the most important aspect of a design layout is to provide alternatives and freedom for users to use a route [30, 31]. This might increase walking, cycling and promote PA. 


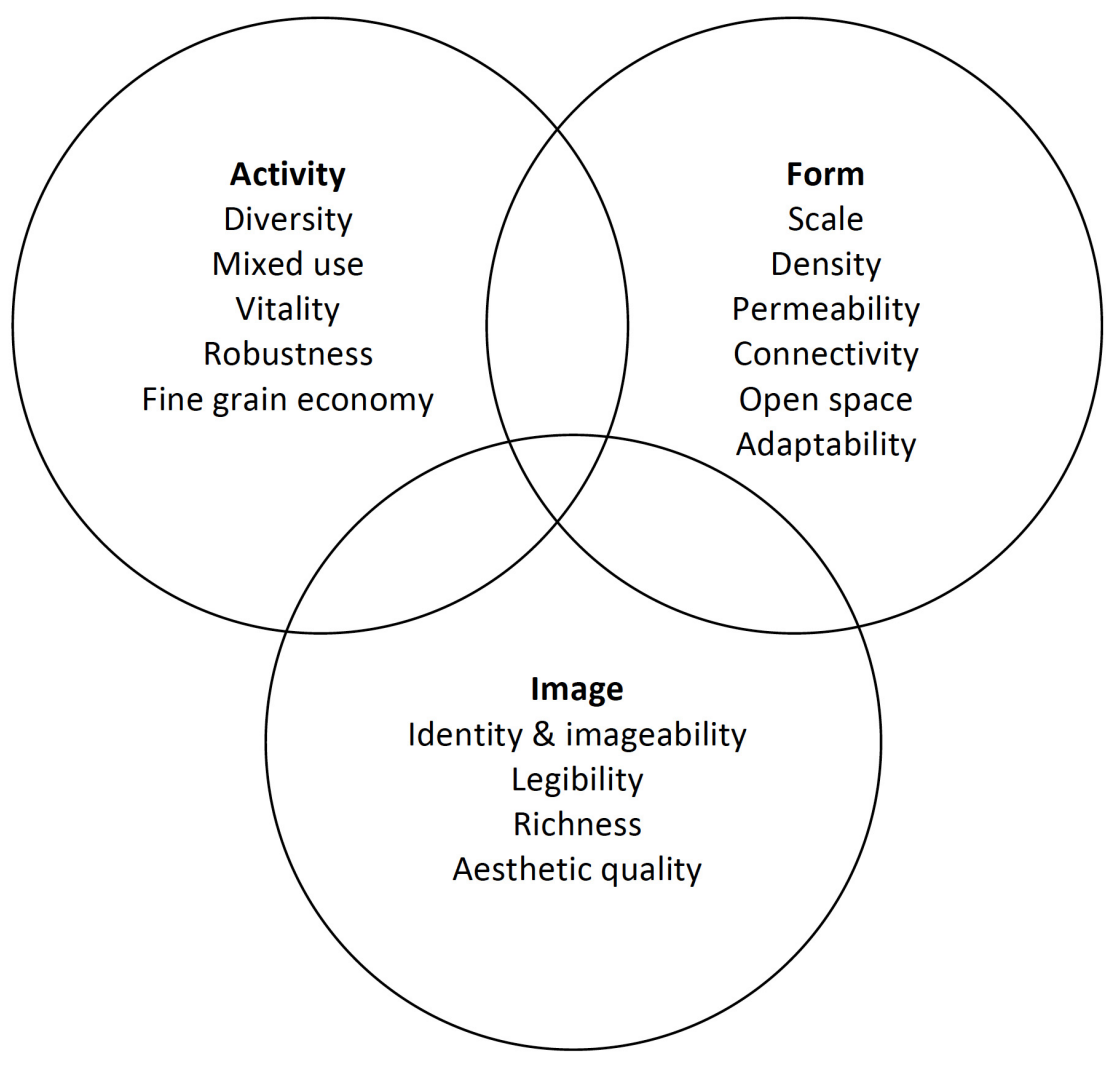

Fig. (2). Urban design elements of place-making. Source: [29, 30].

\section{Vitality and Diversity}

Activity is the combination of two separate concepts: vitality and diversity. Vitality is the quality that distinguishes a successful urban area from unsuccessful urban areas [29]. It refers to the number of people in the public realm during different hours of the day and night, active street life and the number of cultural events and festivals held there throughout the year and whether the place is vibrant [29]. Walking is an elemental way of experiencing place and an enjoyable place often has its own rhythm and feels [35]. Montgomery [29] argues that it is possible to generate vitality by programming events and activities. However, this can only be achieved where there is a diversity of land uses in an area.

Land use segregation has been recognised as one of the leading factors of poor urban design, resulting in decentralisation from both cities and city squares. Due to urban sprawl and segregation of land uses, many of the traditional "trade from open stalls (has been) gradually relocated to small shops along streets and squares, then to increasingly larger shops and supermarkets, and finally to giant shopping malls, usually far from the heart of the city." [36]. Single dominate land use increases the automobile dependency and leading reduced walking and cycling.

Vitality and diversity encourage people to participate in social activities through open space and the public realm. The public realm is not limited to open space and squares, but includes street activities. Use of public space could be encouraged by providing various activities throughout the day to promote social interaction between people of various age and socio-economic groups, and will accumulate the social capital. In order to achieve vitality, design of an area needs to allow diverse activities throughout the day and attract people [31]. Even though a place may be deemed 'beautiful', if its use is limited to one type of activity, that does not attract people all the time and unsafe and generally, it could be regarded as unviable.

\section{Legibility}

Legibility is one of the major characteristics of a walkable neighbourhood, as it is associated with the design of the street network within a development and how easily the area can be navigated. Fig. (3) illustrates how developments with curved streets and numerous cul-de-sacs can cause difficulty of movement for both pedestrians and visitors. A grid street network, on the other hand, enables pedestrians a better understanding of how to move around the development, as well as the ability to see key destinations or landmarks from a number of blocks away, making an area more walkable.

Good legibility refers to the clear spatial structure of a place that is easy to understand and navigate. Legibility facilitates movement of people by providing alternative routes to destinations. Legible structure of the BE might encourage walking and cycling. Street connectivity also plays an important role in enabling residents to feel comfortable and safe when walking. A high quality streetscape and adequate street furniture can improve safety (Fig. 3). Good legibility also relates to a good streetscape. For example, to ensure that the $\mathrm{BE}$ is legible it is necessary to consider design elements such as "clear street pattern(s) and urban structure, with elements to aid the recognition of uses and orient movement" [31]. Table 1 presents details of urban design elements to achieve legibility in the BE. Layout 
design should promote a clear understanding of the relationship between various activities and enable easy mental mapping of the route to activities.

\section{Richness}

Richness refers to the capacity of a particular layout pattern to accommodate complementary urban activities within mixed uses [31]. The richness of a place depends upon the variety of activities available, mixed land use, landscape elements, street furniture, signage and human activity [27]. Mixed land use generally provides social and commercial facilities within easy walking distance. There is also a strong relationship between the quality of the public realm and walking and cycling [37]. Booth et al., [7] argue that a neighbourhood, which comprises a mixture of land uses such as commercial, retail and recreational zones as well as a diverse range of housing types often results in an increase in PA and help reduce obesity and overweight levels. Several authors support this. Forsyth et al., [12] and Saelens et al., [18] recognise that neighbourhoods with optimum density, good street patterns, good pedestrian networks and public transportation facilities, encourage both cycling and walking. Furthermore, Samimi et al., [11] claim that a $1 \%$ decrease in the use of automobiles, for example, can decrease obesity by $0.4 \%$.

Built environments with both high and medium densities and a mixture of land uses have been found to influence the level of obesity in a community [7]. These densities are often in a position to support various social, community and commercial facilities in an area, and therefore can indirectly support walking and cycling.

Richness also means that BE should be pleasing. Many researchers argue that an attractive neighbourhood will encourage PA, as well as greater community participation; whereas living in an unpleasant neighbourhood will discourage walking and overall PA [18, 24, 25].

\section{Open Space}

The provision of open space is well recognised as a major contributor to the quality of health, as well as quality of the urban environment [38, 39]. Several studies demonstrated how rural and urban environments impact on physical and mental health of the population [40-46]. The role of open space is not only for aesthetic value, but also it helps reduce stress level, helps in healing, enhances well-being and provides ground for PA [39, 47-49].

A number of researchers agree that both the social and physical environment play an important role in the improvement of participation in PA [24]. Therefore, location, size and facilities of open space might contribute to PA levels and promote community participation.

Location and the connection to open space are both very important in improving the utilisation of open space and encouraging people to participate in community activities. This will encourage adults accompanying children to public parks and promote greater participation in PA [50]. Cohen et al., [51] argue that there is strong relationship between distance between open space and dwelling units and open space located at a distance of less than one kilometre from the place of residence has a strong correlation with PA.

Table 1 shows the relationship between urban design principles and various PA in order to create a $\mathrm{BE}$ which is responsive to $\mathrm{PA}$. This might ultimately help reducing the percentage of obese and overweight people globally.

\section{DISCUSSION AND CONCLUSIONS}

New design paradigms relating to the BE, such as New Urbanism, Transit Oriented Developments (TOD) and Smart Growth aim to encourage PA in urban areas. These design paradigms recognise walk ability, human-scaled neighbourhoods, mixed land use, location of activities and public space, which help to improve the level of PA. The major components of these theories aim at discouraging use of cars, while ensuring high priority to pedestrians and facilities to promote walkability. These paradigms have so far achieved the aim through high density of developments, containing a mixture of land uses, and a variety of housing types around transport nodes and corridors [52]. The creation of an open space network and attractive public spaces is also encouraged.

The review of the literature demonstrates preliminary evidence of the relationship between the BE, urban design principles and the prevalence of obesity. Built form plays an important role in influencing PA, particularly walking and cycling. However, there are still contradictory results that question the influence of the BE on PA. For example, Wells \& Yang [53], using both cross-sectional and longitudinal data in the South-Eastern United States of America found that "neo-traditional neighbourhood features alone (e.g., sidewalks, front porches, small set-back distances)" cannot influence walking.

In addition, the role of "self-selection" in travel behaviour is gradually being introduced in recent transportation studies [13, 54-57]. Self-selection refers to "the tendency of people to choose locations based on their travel abilities, needs and preferences" [58]. It is possible
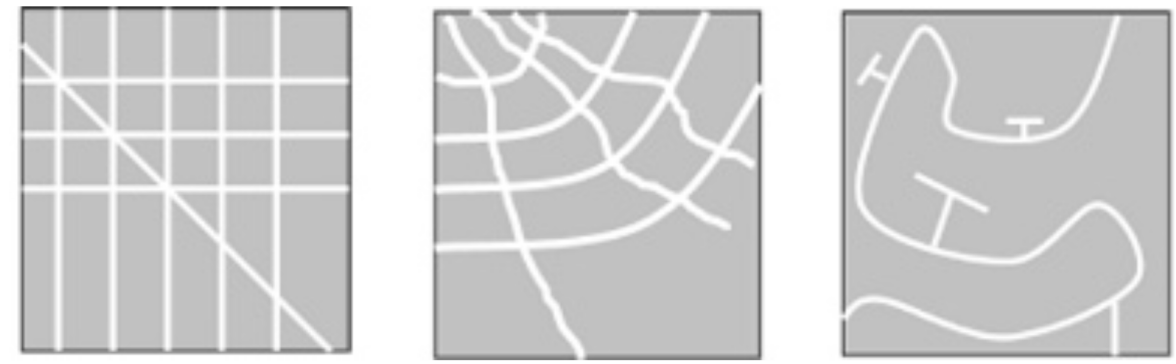

Fig. (3). Legibility of street networks. Source: [34]. 
Table 1. Urban Design Principles Encourage PA

\begin{tabular}{|c|c|c|c|}
\hline Urban Design Principles & \multicolumn{3}{|c|}{ Encourage PA } \\
\hline $\begin{array}{l}\text { Vitality and Diversity } \\
\text { 1. Diversity of activity } \\
\text { 2. Constant activity throughout the day }\end{array}$ & $\begin{array}{l}\sqrt{ } \\
\sqrt{ } \\
\sqrt{ }\end{array}$ & $\begin{array}{l}\sqrt{ } \\
\sqrt{ }\end{array}$ & $\sqrt{ }$ \\
\hline $\begin{array}{l}\text { Legibility } \\
\text { 1. Massing and scale of the building } \\
\text { 2. Location of public space } \\
\text { 3. } \quad \text { Varieties and location of social infrastructure } \\
\text { 4. } \quad \text { Good accessibility } \\
\text { 5. Access to social infrastructure and open space } \\
\text { 6. } \\
\text { 7. }\end{array}$ & $\begin{array}{l}\sqrt{ } \\
\sqrt{ } \\
\sqrt{ } \\
\sqrt{ } \\
\sqrt{ } \\
\sqrt{ } \\
\sqrt{ } \\
\sqrt{ }\end{array}$ & $\begin{array}{l}\sqrt{ } \\
\sqrt{ } \\
\sqrt{ } \\
\sqrt{ }\end{array}$ & $\begin{array}{l}\sqrt{ } \\
\sqrt{ }\end{array}$ \\
\hline $\begin{array}{l}\text { Richness } \\
\text { 1. Housing diversity and choice } \\
\text { 2. Quality of pedestrian walkways and public transport facilities } \\
\text { 3. } \quad \text { Mixed land use } \\
\text { 4. High and medium density }\end{array}$ & $\begin{array}{l}\sqrt{ } \\
\sqrt{ } \\
\sqrt{ } \\
\sqrt{ } \\
\sqrt{ }\end{array}$ & $\begin{array}{l}\sqrt{ } \\
\sqrt{ } \\
\sqrt{ }\end{array}$ & $\sqrt{ }$ \\
\hline \begin{tabular}{ll}
\multicolumn{2}{l}{ Open space } \\
1. & Location \\
2. & Safety \\
3. & Activities \\
4. & Equipments for all age \\
5. & Accessibility
\end{tabular} & $\begin{array}{l}\sqrt{ } \\
\sqrt{ } \\
\sqrt{ } \\
\sqrt{ } \\
\sqrt{ }\end{array}$ & & $\begin{array}{l}\sqrt{ } \\
\sqrt{ } \\
\sqrt{ } \\
\sqrt{ } \\
\sqrt{ }\end{array}$ \\
\hline
\end{tabular}

Source: [29-31] and authors.

that people, who prefer to walk, choose walkable neighbourhoods in which to live. This issue raises questions relating to the observed relationships between the $\mathrm{BE}$ and walking. However, in a recent study $\mathrm{Cao}$ et al., [57] reviewed 38 empirical studies and found a statistically significant influence of the $\mathrm{BE}$ on travel behaviour, after accounting for the self-selection issue.

During the past decade majority of studies examining the relationship between $\mathrm{BE}$ and $\mathrm{PA}$ have been undertaken in relation to public health. Regardless of the classic urban design literature $[37,59,60]$ that emphasised on the walkable $\mathrm{BE}$, there is not much research by the $\mathrm{BE}$ professionals in this field. Therefore, it is necessary that urban designers should collaborate with public health experts and examine the influence of the BE on PA. For example Boarnet \& Takahashi [61] state that public health mainly considers "BE" as the same as "urban design". This means the focus is more on the BE as "an outcome of urban design" rather than urban design as a process in itself. Collaborative works by urban designers and public health scholars can extend the current knowledge in this field.
Designing for more active communities not only addresses the issues associated with obesity, but also complements other objectives including reducing urban sprawl, reducing greenhouse gas emissions, increasing cycling and the use of public transport, as well as increase in the supply of affordable and sustainable housing. The key message is that urban design qualities can lead to welldesigned $\mathrm{BE}$, which will contribute to reducing obesity levels.

\section{ACKNOWLEDGEMENT}

The authors would like to appreciate the insightful comments of the two reviewers of the paper.

\section{CONFLICT OF INTEREST}

Declared none.

\section{REFERENCES}

[1] Cohen DA. Obesity and the built environment: changes in environmental cues cause energy imbalances. Int J Obesity 2008; 32(S7): S137-S42.

[2] World Health Organisation. Global health risks: mortality and burden of disease attributable to selected major 2009. 
[3] Puska P, Nishida C, Porter D. Global strategy on diet, physical activity and health: obesity and overweight obesity and overweight. World Health Organisation 2003.

[4] Feng J, Glass TA, Curriero FC, Stewart WF, Schwartz BS. The built environment and obesity: a systematic review of the epidemiologic evidence. Health Place 2010; 16(2): 175-90.

[5] Australian bureau of statistics, national health survey2007-08, CAT. NO. 4364.0. 2009, CANBERRA.

[6] World Health Organisation, Obesity and overweight. Fact sheet No311. 2006.

[7] Booth KM, Pinkston MM, Poston WSC. Obesity and the built environment. J Am Diet Assoc 2005; 105(5 Suppl 1): 110-7.

[8] Leyden KM. Social capital and the built environment: the importance of walk able neighborhoods. Am J Public Health 2003; 93(9): 1546-51.

[9] Jackson R. The impact of the built environment on health: an emerging field. Am J Public Health 2003; 93(9): 1382-4.

[10] Perdue WC, Stone LA, Gostin LO. The built environment and its relationship to the public's health: the legal framework. Am J Public Health 2003; 93: 1390-4.

[11] Samimi A, Mohammadian A, Madanizadeh S. Effects of transportation and built environment on general health and obesity. Transp Res Part D Transp Environ 2009; 14(1): 67-71.

[12] Forsyth A, Oakes JM, Lee B, Schmitz KH. The built environment, walking, and physical activity: is the environment more important to some people than others? Transp Res Part D Transp Environ 2009; 14(1): 42-9.

[13] Frank LD, Saelens BE, Powell KE, Chapman JE. Stepping towards causation: do built environments or neighborhood and travel preferences explain physical activity, driving, and obesity? Soc Sci Med 2007; 65(9): 1898-914.

[14] Frank LD, Andresen MA, Schmid TL. Obesity relationships with community design, physical activity, and time spent in cars. Am J Prev Med 2004; 27(2): 87-96.

[15] Lopez R, Hynes HP. Obesity, physical activity, and the urban environment: public health research needs. Environ Health 2006; 5(1): 25 .

[16] Lopez R. Urban sprawl and risk for being overweight or obese. Am J Public Health 2004; 94(9): 1574-9.

[17] Kelly-Schwartz A, Stockard J, Doyle S, Schlossberg M. Is sprawl unhealthy? A multi-level analysis of the relationship of metropolitan sprawl to the health of individuals. J Plan Educ Res 2004; 24(2): 184-96.

[18] Saelens BE, JF Sallis, JB Black, D Chen. Neighborhood-based differences in physical activity: an environment scale evaluation. Am J Public Health 2003; 93(9): 1552-8.

[19] Black JL, Macinko J, Dixon LB, Fryer JGE. Neighborhoods and obesity in New York City. Health Place 2010; 16(3): 489-99.

[20] Roemmich JN, Epstein LH, Raja S, Yin L, Robinson J, Winiewicz D. Association of access to parks and recreational facilities with the physical activity of young children. Prev Med 2006; 43(6): 437-41.

[21] Gordon-Larsen P, Nelson MC, Page P, Popkin BM. Inequality in the built environment underlies key health disparities in physical activity and obesity. Pediatrics 2006; 117(2): 417-24

[22] Mobley LR, Root ED, Finkelstein EA, Khavjou O, Farris RP, Will JC. Environment, obesity, and cardiovascular disease risk in lowincome women. Am J Prev Med 2006; 30(4): 327-32.

[23] Jackson R, Kochtitzky C. Creating a healthy environment: the impact of the built environment on public health. Washington DC: Sprawl Watch Clearinghouse 2001.

[24] Poortinga W. Perceptions of the environment, physical activity, and obesity. Soc Sci Med 2006; 63(11): 2835-46.

[25] Duncan M, Mummery K. Psychosocial and environmental factors associated with physical activity among city dwellers in regional Queensland. Prev Med 2005; 40(4): 363-72.

[26] Sallis J, Cervero R, Ascher W, Henderson K, Kraft M, Kerr J. An ecological approach to creating active living communities. Ann Rev Pub Health 2006; 27: 297-322.

[27] Ewing R, Handy S. Measuring the unmeasurable: urban design qualities related to walkability. J Urban Des 2009; 14(1): 65-84.

[28] Llewelyn-Davies. Urban design compendium. London: English Partnerships/The Housing Corporation 2000.
[29] Montgomery J. Making a city: urbanity, vitality and urban design. J Urban Des 1998; 3(1): 93-116.

[30] Bentley I., Alcock A, Murrain P, McGlynn S, Smith G. Responsive environments: a manual for designers. Oxford: Architectural Press 1985

[31] Schiller SD, Evans JM. Assessing urban sustainability: microclimate and design qualities of a new development, in the 23rd conference on passive and low energy architecture: Geneva, Switzerland 2006.

[32] Kozlowski M. The emergence of urban design in regional and metropolitan planning: the Australian context. Aust Plann 2006; 43(1): 36-41.

[33] DETR, By design. Urban design in the planning system: towards better practice. London: DETR 2000.

[34] Zeibots M, Mason L. Walkable neighbourhoods 2008 [Cited: $20^{\text {th }}$ June 2011]; Available from: http://yourdevelopment.org/factsheet/ view/id/70.

[35] Wunderlich FM. Walking and rhythmicity: sensing urban space. J Urban Des 2008; 13(1): 125-39.

[36] Gehl J, Gemzøe L. New city spaces. $3^{\text {rd }}$ ed. Copenhagen: Danish Architectural Press 2003.

[37] Gehl J. Life between buildings: using public space. New York: Van Nostrand Reinhold 1987.

[38] Kaplan R, Kaplan S. The experience of nature: a psychological perspective: Cambridge: Cambridge University Press 1989.

[39] Ulrich RS. View through window may influence recovery from surgery. Science 1984; 224: 420-1.

[40] Relf D, Ed. The role of horticulture in human well-being and social development. Portland, Oregon: Timber Press 1992 ,

[41] Wilson EO. Biophilia. Cambridge, MA: Harvard University Press 1984

[42] Freeman H, Ed. Mental health and the environment. London: Churchill Livingstone 1984.

[43] Ulrich RS, Parsons R. Influences of passive experiences with plants on individual wellbeing and health. The role of horticulture in human well-being and social development: a national symposium, D. Relf, Ed. Portland, Oregon: Timber Press 1992; pp. 93-105.

[44] Sooman A, Macintyre S. Health and perceptions of the local environment in socially contrasting neighbourhoods in Glasgow. Health and Place 1995; 1(1): 15-26.

[45] Lundberg A, Ed. Introduction' and 'environmental change and human health, environment and mental health. London: Lawrence Erlbaum 1998; pp. 1-4 and 5-25.

[46] Pacione M. Urban environmental quality and human wellbeing - a social geographical perspective. Landscape Urban Plan 2003; 986: $1-12$.

[47] Ulrich RS. Visual landscapes and psychological well being. Landscape Res 1979; 4: 17-23.

[48] Ulrich RS. Natural vs urban scenes: some psychophysiological effects. Environ Behav 1981; 13: 523-56.

[49] Ulrich RS. Stress recovery during exposure to natural and urban environments. J Environ Psychol 1991; 11: 201-30.

[50] Cohen DA, McKenzie TL, Sehgal A, Williamson S, Golinelli D, Lurie N. Contribution of public parks to physical activity. Am J Public Health 2007; 97(3): 509-14.

[51] Cohen DA, Ashwood JS, Scott MM. Public parks and physical activity among adolescent girls. Pediatrics 2006; 118(5): e1381-9.

[52] Grant J. The ironies of new urbanism. Can J Urban Res 2006; 15(2): 158-74

[53] Wells NM, Yang Y. Neighborhood design and walking: a quasiexperimental longitudinal study. Am J Prev Med 2008; 34(4): 3139.

[54] Handy S, Cao X, Mokhtarian P. Correlation or causality between the built environment and travel behavior? Evidence from Northern California. Transp Res Part D Transp Environ 2005; 10(6): 427-44.

[55] Handy S, Cao X, Mokhtarian PL. Self-selection in the relationship between the built environment and walking: empirical evidence from Northern California. J Am Plann Assoc 2006; 72(1): 55-74.

[56] Mokhtarian PL, Cao X. Examining the impacts of residential selfselection on travel behavior: A focus on methodologies. Transp Res Part B: Methodological 2008; 42(3): 204-28. 
[57] Cao X, Mokhtarian PL, Handy SL. Examining the impacts of residential self-selection on travel behaviour: a focus on empirical findings. Transp Rev 2009; 29(3): 359-95.

[58] Litman TA. Land use impacts on transport: how land use factors affect travel behavior. 2005, Victoria Transport Institute. Available at: www.vtpi.org/landtravel.pdf [Accessed: November 12, 2010].
[59]

Appleyard D, Gerson MS, Lintell M. Livable streets protected neighborhoods. Berkeley: Institute of urban and regional development, University of California 1977.

[60] Jacobs J. The death and life of great American cities.: New York: Vintage Books 1963.

[61] Boarnet MC, Takahashi LM. Interactions between public health and urban design, in Companion to Urban Design, T. Banerjee and A. Loukaitou-Sideris, Ed. New York: Routledge 2011; pp. 198-207.

(c) Sivam et al.; Licensee Bentham Open.

This is an open access article licensed under the terms of the Creative Commons Attribution Non-Commercial License (http://creativecommons.org/licenses/by$\mathrm{nc} / 3.0 /$ ) which permits unrestricted, non-commercial use, distribution and reproduction in any medium, provided the work is properly cited. 